\title{
A Patient With Dysphagia Associated With Opioid Medication
}

\author{
Kee Wook Jung, Seung-Jae Myung and Hwoon-Yong Jung* \\ Asan Digestive Disease Research Institute, Department of Gastroenterology, University of Ulsan College of Medicine, Asan Medical Center, \\ Seoul, Korea
}

A 40-year-old male visited Asan Medical Center complaining of dysphagia, which he had experienced for about six months. His medical history indicated that he had suffered from pulmonary tuberculosis with destructive lung, and took various medications to control his chronic cough. He denied any symptom of heartburn or acid regurgitation. Upper endoscopy findings were normal. The barium esophagogram showed no definite abnor- malies. However, esophageal manometry revealed nutcracker esophagus with a mean distal esophageal amplitude of 213.0 $\mathrm{mmHg}$ (resting lower esophageal sphincter pressure was 22.9 $\mathrm{mmHg}$ ). He was taking many medications as needed, including codeine $20 \mathrm{mg}$, to control his frequent cough (more than 10 times/day). He also complained of chronic constipation after taking too many codeine tablets. At his second visit, he was in-

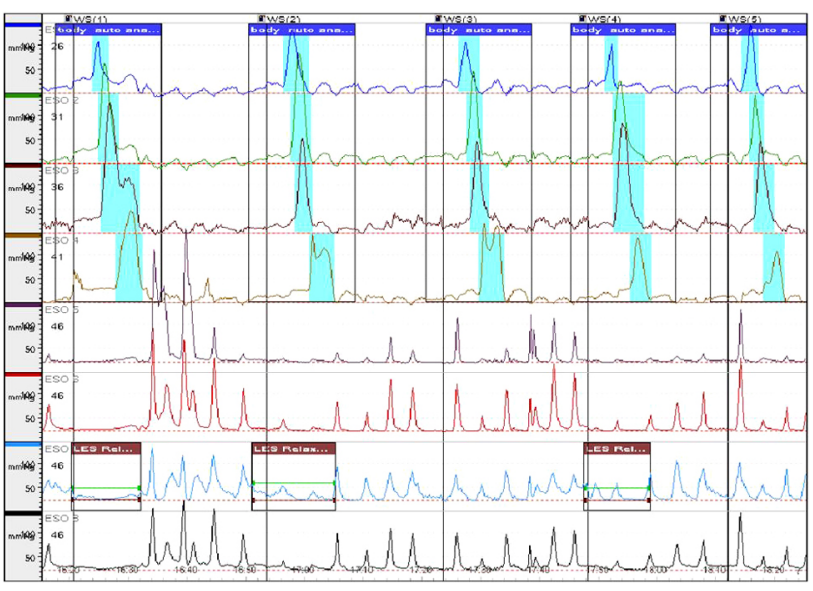

Figure 1. Esophageal manometry at first visit showed increased mean distal esophageal amplitude of $213.0 \mathrm{mmHg}$ with intact peristalsis.

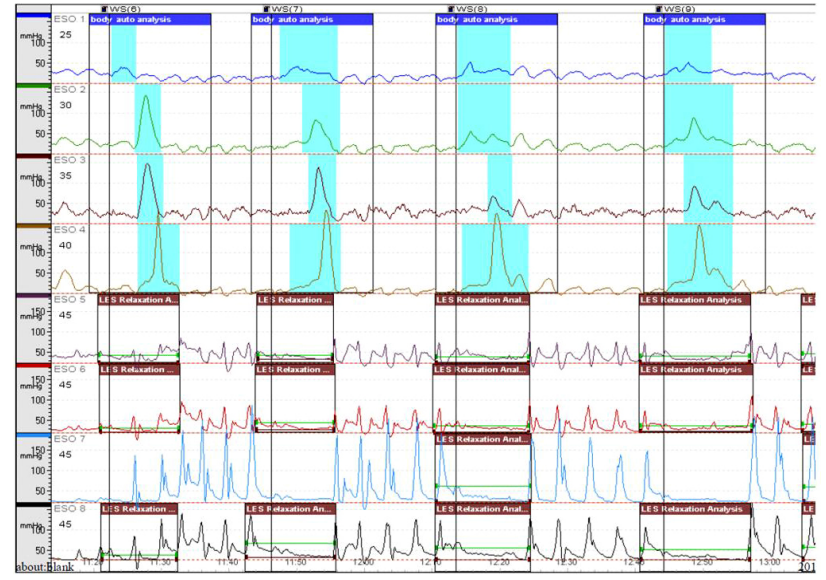

Figure 2. Follow-up esophageal manometry showed decreased mean distal esophageal amplitude of $161.6 \mathrm{mmHg}$.

Received: February 9, 2012 Revised: February 20, 2012 Accepted: February 29, 2012

(c) This is an Open Access article distributed under the terms of the Creative Commons Attribution Non-Commercial License (http://creativecommons. org/licenses/by-nc/3.0) which permits unrestricted non-commercial use, distribution, and reproduction in any medium, provided the original work is properly cited.

*Correspondence: Hwoon-Yong Jung, MD

Asan Digestive Disease Research Institute, Department of Gastroenterology, University of Ulsan College of Medicine, Asan Medical Center, 88 Olympic-ro 43-gil, Songpa-gu, Seoul 138-736, Korea

Financial support: None.

Tel: +82-2-3010-3197, Fax: +82-2-476-0824, E-mail: hyjung@amc.seoul.kr

Conflicts of interest: None. 
structed to decrease the use of codeine to 3 times per day. After reducing the dosage of codeine, the dysphagia improved. Four months later, a follow-up esophageal manometry was performed and it showed normal peristalsis without evidence of nutcracker esophagus, with a mean distal esophageal amplitude of 161.6 $\mathrm{mmHg}$ (resting lower esophageal sphincter pressure was 27.1 $\mathrm{mmHg})$.

Experimental evidence of opioid-induced esophageal dysmotility has been provided in several papers. ${ }^{1,2}$ However, clinical manifestations of this condition were recently presented only in case reports from the Mayo clinic. ${ }^{3,4}$ The lower esophageal sphincter and distal esophageal body are known to be vulnerable to chronic use of opioid medications with mu type opioid agonist function. ${ }^{1,3}$ The reason for this is not perfectly clear, however, the nitric oxide pathway is thought to be involved. ${ }^{3,4}$

\section{References}

1. Penagini R, Bianchi PA. Effect of morphine on gastroesophageal reflux and transient lower esophageal sphincter relaxation. Gastroenterology 1997;113:409-414.

2. Penagini, Bartesaghi B, Negri G, Bianchi PA. Effect of loperamide on lower oesophageal sphincter pressure in idiopathic achalasia. Scand J Gastroenterol 1994;29:1057-1060.

3. Kraichely RE, Arora AS, Murray JA. Opiate-induced oesophageal dysmotility. Aliment Pharmacol Ther 2010;31:601-606.

4. Jung KW, Kraichely RE, Arora AS, Romero Y, Katzka DA, Murray JA. Manometric characteristics of opioid esophageal dysmotility disorder by high-resolution manometry. Gastroenterology 2011;140:S229. 